\title{
A RISK-BASED METHODOLOGY TO ASSESS RUN-OFF-ROAD CRASHES ON AUSTRIAN MOTORWAYS - THE RISKANT PROJECT
}

\author{
C. STEFAN ${ }^{1}$, R. STÜTZ ${ }^{1}$, E. TOMASCH ${ }^{2}$, P. LUTTENBERGER ${ }^{2} \&$ C. KLEIN ${ }^{2}$ \\ ${ }^{1}$ AIT Austrian Institute of Technology, Mobility Department, Austria. \\ ${ }^{2}$ Graz University of Technology, Vehicle Safety Institute, Austria.
}

\begin{abstract}
Run-off-road (ROR) crashes are extremely severe road accidents that often result in serious injuries or fatalities. On Austrian motorways, about $40 \%$ of all injury accidents are ROR crashes, which account for more than $60 \%$ of the fatalities on the primary road network. This is one of the reasons why the Austrian highway operator (ASFINAG) postulates in its road safety program till 2020 that new safety strategies and new road safety measures have to be developed to prevent vehicles from running off the road and (in a worst case scenario) collide with stationary obstacles on the roadside. RISKANT is a research project funded within the 2011 Call "Transportation Infrastructure Research (VIF)" of the Austrian Research Promotion Agency (FFG) in conjunction with ASFINAG. The main objective of RISKANT was to develop a risk model for crashes with stationary obstacles along the roadside. In order to achieve this goal, a so-called accident prediction model was used to estimate the probabilities of ROR crashes due to the characteristics of the road and the road environment. Furthermore, Finite element simulation studies were conducted to incorporate the severity of injuries due to collisions with different stationary obstacles. Two indices, the Acceleration Severity Index (ASI) and Theoretical Head Impact Velocity (THIV) were used to evaluate the injury risk level for vehicle occupants.

Keywords: accident prediction, crash simulation, model, risk model, run-off-road crashes, safety performance function, stationary obstacles.
\end{abstract}

\section{INTRODUCTION}

\subsection{Analysis of road crashes}

Run-off-road (ROR) crashes are road accidents that often result in severe injuries or fatalities. Their relevance as a traffic safety issue has already been demonstrated in a number of European research projects. The accident analysis conducted within the RISER project [1] highlighted for example that even though only $10 \%$ of the total number of accidents are single vehicle accidents (typically associated with ROR crashes), the rate of single vehicle events increase up to $45 \%$ when only fatal accidents are considered.

According to Statistics Austria [2], one fifth of all injury accidents on Austrian roads in the period 2007-2011 include at least one of the vehicles involved running off the road. The majority $(83 \%)$ being single vehicle crashes.

Due to their unique traffic conditions (one-way traffic, motorized vehicles only, etc.), figures on Austrian motorways are even higher than the overall average. As shown in Fig. 1, nearly half (44\%) of the crashes occurring on the primary road network are ROR crashes, 


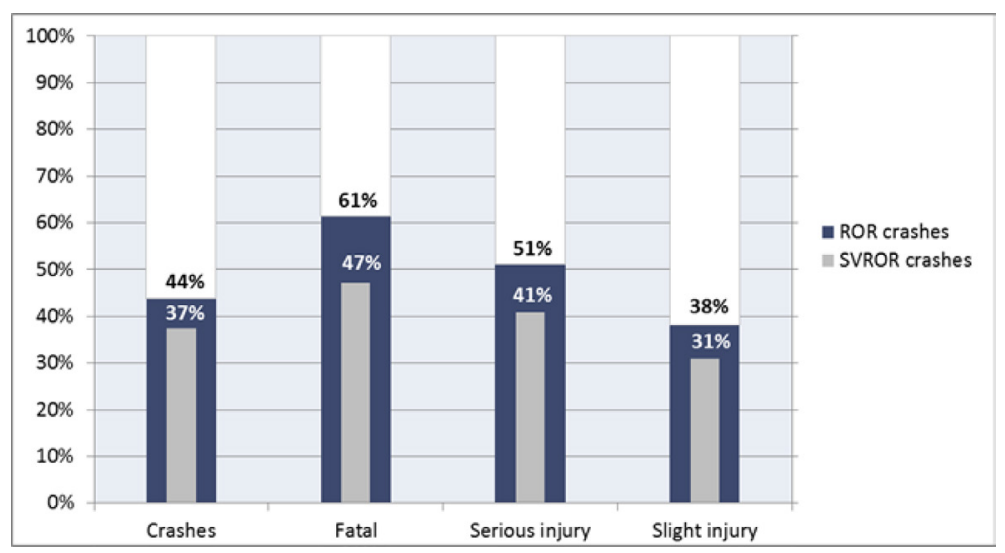

Figure 1: Proportion of ROR and single vehicle run-off-road (SVROR) crashes of all crashes on motorways.

$37 \%$ of the crashes involving only one vehicle (SVROR crashes). ROR crashes are responsible for more than $60 \%$ of the road fatalities and $51 \%$ of the seriously injured on motorways.

To reduce the severity of ROR crashes, "forgiving roadsides" need to be designed which includes identifying situations where the probability of suffering a ROR crash are extremely high and/or where roadside obstacles pose a disproportionate risk to traffic participants due to their structure and rigidity.

\subsection{Risk-based decision support models to increase road safety}

The Austrian highway operator (ASFINAG) faces many challenges in managing the accident risk on its road network, with fewer accident prone sites, increased use of active traffic management more demanding performance targets and less funding. It now takes the view that an innovative road infrastructure safety strategy requires a holistic approach by combining riskbased methodologies with existing cost-efficient and practical solutions in order to manage road safety on a regional and network level.

Hence, risk-based decision support models in the field of traffic safety are considered as an instrument for reviewing the transportation network to identify potential hazards to traffic participants and road operations. In comparison to a traditional reactive approach, which relies on analyses of available historical accident data to detect hazardous and accident prone situations, a proactive system is based on the analysis of physical and operational characteristics of existing roads or road projects to identify actual or future safety deficiencies.

Accident Prediction Models (APMs) are special forms of risk models that estimate the long-term expected accident frequency for a specific site type (i.e. road site with specified base conditions) as a function of several risk factors: exposure, driven speed, road curvature etc. (see Fig. 2) Data from untreated reference sites are generally used to estimate APMs.

There are generally two types of APMs (also called SPF, Safety Performance Functions) that have been used in the literature: (1) full SPFs and (2) simple SPFs. The full SPF relates the frequency of crashes to both traffic and roadway characteristics, whereas the simple SPF considers a traffic parameter only, such as AADT, annual average daily traffic, as an explan- 


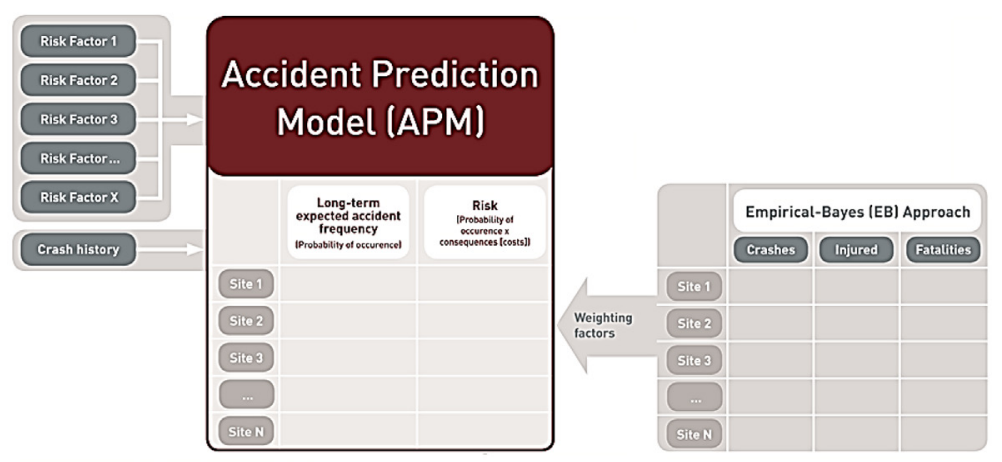

Figure 2: Concept of a risk-based decision support model.

atory variable. In this study, the full SPF was used with the EB method since the simple SPF is an over-simplified function [3].

\section{DATA DESCRIPTION AND PREPARATION}

Within this study, data from different sources had to be prepared, adjusted and pre-processed to obtain a merged, single data set.

AIT is the operator of a high-performance measurement truck [4], which was used to measure all relevant parameters for pavement management and road safety, i.e. skid resistance, transverse and longitudinal evenness, curve radii, gradient, crossfall, water film thickness. The mobile measurement system (called RoadSTAR) is capable of measuring these parameters under normal traffic conditions at speeds between 40 and $120 \mathrm{~km} / \mathrm{h}$ (standard measurement speed $60 \mathrm{~km} / \mathrm{h}$ ) in a single run. Furthermore, it is equipped with an inertial measurement unit (IMU), a differential GPS for referencing the measurement data to their position. Road geometry parameters were derived from the IMU, while texture and evenness were measured with different laser scanning systems. Camera systems provided additional information about surface defects and the road environment (traffic signs, lane widths etc.).

The Austrian motorways are periodically monitored every 5 years. For the underlying study, RoadSTAR measurement data were available for the year 2009.

Accident records have been collected by the Austrian Bureau of Statistics (Statistics Austria). This study is based on a dataset of all Austrian road accidents with physical injuries in the observation period 2005-2011.

Traffic volumes were provided by ASFINAG for the period 2006-2010. The dataset contains the AADT on pre-defined road sections (for all vehicles and HGVs or heavy goods vehicles, respectively).

As a first step, a merged dataset with a resolution of $1 \mathrm{~m}$ was created for the whole motorway network, which is described in Table 1 . In order to model the frequency of accidents as a function of road condition, road geometry and traffic parameters, the ASFINAG network was divided into sections with a fixed length of $250 \mathrm{~m}$. Note that the segment length cannot be arbitrary small, since there would be a high number of segments without accidents, resulting in too many zeros in the sample.

Several statistics (median, standard deviations, quantiles etc.), which can be directly included in the models, were calculated to obtain characteristic values from the longitudinal 
Table 1: Data set description.

\begin{tabular}{|c|c|}
\hline Variable name & Description \\
\hline \multicolumn{2}{|l|}{ Accident Data } \\
\hline acc_total & all accidents with physical injury during period 2005-2011 \\
\hline acc_ror & ROR accidents with physical injury during period 2005-2011 \\
\hline \multicolumn{2}{|l|}{ Road condition } \\
\hline skid_res & skid resistance $[-]$ \\
\hline wdepth & water film thickness [mm] (ruts) \\
\hline \multicolumn{2}{|l|}{ Road geometry } \\
\hline bendiness & $\begin{array}{l}\text { bendiness of road defined as the mean absolute change of heading } \\
\text { angles }[\mathrm{Gon} / \mathrm{m}]\end{array}$ \\
\hline gradient & longitudinal slope road [\%] \\
\hline crossfall & horizontal slope of road [\%] \\
\hline crossfall_zero_ind & indicator variable if crossfall is zero \\
\hline \multicolumn{2}{|l|}{ Road environment } \\
\hline speed & $\begin{array}{l}\text { posed speed limit (categorical; levels } 80,100,130 \mathrm{~km} / \mathrm{h} \text {; reference } \\
\text { value } 130 \mathrm{~km} / \mathrm{h} \text { ) }\end{array}$ \\
\hline lanes & $\begin{array}{l}\text { number of lanes (categorical; levels 2, 3, 4; reference value } 2 \\
\text { lanes) }\end{array}$ \\
\hline lane_ind & $\begin{array}{l}\text { indicator variable for presence of lane reduction/expansion } \\
\text { (categorical; values 'none', 'exp', 'red'; reference value 'none') }\end{array}$ \\
\hline tunnel_ind & indicator variable for presence of road tunnels \\
\hline emlane_ind & indicator variable for presence of emergency lanes \\
\hline \multicolumn{2}{|c|}{ Traffic characteristics } \\
\hline AADT & $\begin{array}{l}\text { annual averaged daily traffic }(\mathrm{veh} / 24 \mathrm{~h}) \text {; median value in period } \\
2006-2010\end{array}$ \\
\hline $\mathrm{HGV} \%$ & proportion of $\mathrm{HGVs}$ in AADT \\
\hline
\end{tabular}

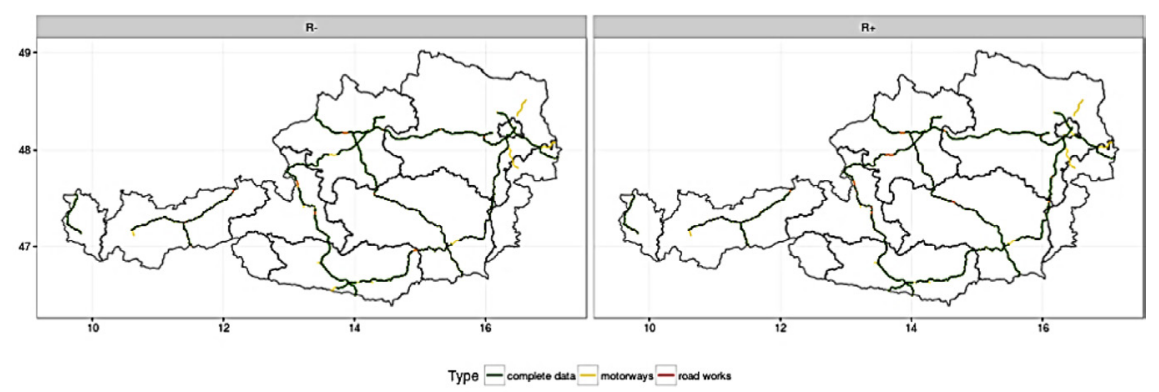

Figure 3: Austrian motorway network and available segments for model building (R+/Rincreasing/decreasing kilometrage. 
parameters on each segment. The Austrian motorway network is illustrated in Fig. 3, segments without missing values (green) were used during the statistical modelling process.

\section{METHODOLOGY}

\subsection{Run-off-road accident prediction model for motorways}

APMs can be considered as regression models for count data, Poisson and negative binomial (NB) regression being the most widely used models for count data. These two belong to the larger class of generalized linear models, which are well developed statistical methodologies [5].

A basic general linear model, GLM, consists of the following three elements: (1) the response $y$ has a particular distribution form from the exponential family; (2) a linear predictor $\eta=X \beta$, where $X$ denotes the vector of covariates and the coefficients $\beta$ are to be estimated; and (3) a link function $g$, which connects the mean $\mu$ of the response to the linear predictor $\eta$, i.e. $g(\mu)=\eta$.

Poisson regression models are GLMs with the natural logarithm as canonical link function, and the Poisson distribution function as the assumed probability distribution of the response. A characteristic property of the Poisson distribution is that the variance equals the mean $\operatorname{Var}[Y]=E[Y]=\mu$ (equidispersion). Empirically, however, the data often exhibits a so-called over-dispersion, i.e. a variance larger than the mean. There are several ways to overcome over-dispersion. A popular choice is the NB-model which is basically a Poisson-gamma mixture model with a second ancillary parameter $\theta$.

The marginal distribution is a NB distribution with mean and variance given by $E[Y]=\mu$ and $\operatorname{Var}[Y]=\mu+\frac{\mu^{2}}{\theta}$. According to [6] the NB-model is the probably the most frequently used for APM.

Table 2: Summary of selected NB-models.

\begin{tabular}{lll}
\hline Variable & NB-model all accidents & NB-model ROR accidents \\
\hline intercept & $-1.54 \mathrm{e}+00 * * *$ & $-1.73 \mathrm{e}+00^{* * *}$ \\
& $(1.99 \mathrm{e}-01)$ & $(2.99 \mathrm{e}-01)$ \\
AADT & $1.04 \mathrm{e}-04 * * *$ & $4.86 \mathrm{e}-05^{* * *}$ \\
& $(6.39 \mathrm{e}-06)$ & $(8.73 \mathrm{e}-06)$ \\
AADT $^{2}$ & $-1.04 \mathrm{e}-09 * * *$ & $-3.98 \mathrm{e}-10 * *$ \\
& $(1.21 \mathrm{e}-10)$ & $(1.42 \mathrm{e}-10)$ \\
HGV\% & $1.44 \mathrm{e}-02 * * *$ & $2.57 \mathrm{e}-02 * * *$ \\
& $(3.97 \mathrm{e}-03)$ & $(5.38 \mathrm{e}-03)$ \\
speed=100 & & $-2.19 \mathrm{e}-01 * *$ \\
& & $(8.40 \mathrm{e}-02)$ \\
speed=80 & & $-1.28 \mathrm{e}+00^{* * *}$ \\
& & $(1.85 \mathrm{e}-01)$ \\
\hline
\end{tabular}

(Continued) 
Table 2: (Continued)

\begin{tabular}{|c|c|c|}
\hline Variable & NB-model all accidents & NB-model ROR accidents \\
\hline lanes $=3$ & $\begin{array}{l}-5.56 \mathrm{e}-02 \\
(1.45 \mathrm{e}-01)\end{array}$ & $\begin{array}{l}9.98 \mathrm{e}-03 \\
(7.35 \mathrm{e}-02)\end{array}$ \\
\hline lanes $=4$ & $\begin{array}{l}-1.48 \mathrm{e}+00^{* *} \\
(5.29 \mathrm{e}-01)\end{array}$ & $\begin{array}{l}5.42 \mathrm{e}-01 * \\
(2.17 \mathrm{e}-01)\end{array}$ \\
\hline bendiness & $\begin{array}{l}3.28 \mathrm{e}+00 * * * \\
(7.18 \mathrm{e}-01)\end{array}$ & $\begin{array}{l}7.71 \mathrm{e}+00 * * * \\
(1.03 \mathrm{e}+00)\end{array}$ \\
\hline median(skid_res) & $\begin{array}{l}-8.62 \mathrm{e}-01 * * * \\
(2.19 \mathrm{e}-01)\end{array}$ & $\begin{array}{l}-1.22 \mathrm{e}+00 * * * \\
(3.26 \mathrm{e}-01)\end{array}$ \\
\hline sd(skid_res) & $\begin{array}{l}2.35 \mathrm{e}+00^{* *} \\
(8.18 \mathrm{e}-01)\end{array}$ & \\
\hline median(crossfall) & & $\begin{array}{l}-1.52 \mathrm{e}-02 * \\
(7.35 \mathrm{e}-03)\end{array}$ \\
\hline median(gradient) & & $\begin{array}{l}-7.69 \mathrm{e}-02 * * * \\
(1.53 \mathrm{e}-02)\end{array}$ \\
\hline tunnel_ind & $\begin{array}{l}-1.35 \mathrm{e}-01 \\
(7.51 \mathrm{e}-02)\end{array}$ & $\begin{array}{l}-3.26 \mathrm{e}-01 \\
(1.72 \mathrm{e}-01)\end{array}$ \\
\hline emlane_ind & & $\begin{array}{l}2.73 \mathrm{e}-01 \\
(1.40 \mathrm{e}-01)\end{array}$ \\
\hline lane_ind=exp & $\begin{array}{l}5.75 \mathrm{e}-01 * \\
(2.45 \mathrm{e}-01)\end{array}$ & \\
\hline lane_ind=red & $\begin{array}{l}4.75 \mathrm{e}-01 * \\
(2.26 \mathrm{e}-01)\end{array}$ & \\
\hline crossfall_zero_ind & $\begin{array}{l}1.82 \mathrm{e}-01 * * * \\
(4.97 \mathrm{e}-02)\end{array}$ & $\begin{array}{l}3.22 \mathrm{e}-01 * * * \\
(6.99 \mathrm{e}-02)\end{array}$ \\
\hline median(wdepth) & $\begin{array}{l}-7.60 \mathrm{e}-02 * * \\
(2.67 \mathrm{e}-02)\end{array}$ & $\begin{array}{l}-4.90 \mathrm{e}-02 * * * \\
(1.26 \mathrm{e}-02)\end{array}$ \\
\hline median(wdepth) ${ }^{2}$ & $\begin{array}{l}3.65 e-03 \\
(2.24 e-03)\end{array}$ & \\
\hline interaction & $-1.58 \mathrm{e}-06$ & \\
\hline AADT - lanes $=3$ & $(5.34 \mathrm{e}-06)$ & \\
\hline interaction & $3.95 \mathrm{e}-05 * * *$ & \\
\hline $\mathrm{AADT}-$ lanes $=4$ & $(1.15 \mathrm{e}-05)$ & \\
\hline \# observations & 7,650 & 7,650 \\
\hline
\end{tabular}

standard errors in parentheses

significant at '.'p < .10; ‘ $*$ ’ $\mathrm{p}<.05 ;$; $* *$ ’ $\mathrm{p}<.01$; ‘ $* * *$ ’ $\mathrm{p}<.001$

Two different models were fitted, one model for all accidents as dependent variable, and a second model only for ROR crashes. A summary of the final models for road segments without intersections after model selection are shown in Table 2. Due to the application of variable selection techniques, different sets of covariates are present in the models.

The presented models yield an estimate of the expected number of accidents for roadway segments with a certain combination of traits. Obviously the models do not include all factors 
which produce a (systematic) variation in accident counts; like local weather, driver behaviour, vehicles, etc. Thus, the expected number of accidents for a specific segment will usually differ from the mean value for segments that have similar properties.

A framework for combining the information contained in observed accident counts on a specific segment with the averaged accident information contained in similar segments from the APM is the empirical Bayes (EB) method [7, 8]. The EB procedure increases the precision of estimation and corrects for the regression-to-mean bias.

Using the EB method, the best estimate $\tilde{y}$ of the expected number of accidents for a given segment is given by the convex combination $\tilde{y}=w \hat{y}+(1-w) y$, where $y$ denotes the observed accident count and $\hat{y}$ is the expected value from the APM. The weight $w$ is determined using the dispersion parameter $\theta$ of the NB distribution, $w=1 /\left(1+\frac{y}{\theta}\right)$.

To quantify the risk of ROR crashes on a specific segment, the ratios of the APM predictions are compared with the ratios of the EB-weighted predictions from both models, i.e. the values for the relative risks $R_{\mathrm{APM}}=\frac{\hat{y}_{\text {Total }}}{\hat{y}_{\mathrm{ROR}}}$ and $R_{\mathrm{EB}}=\frac{\tilde{y}_{\text {Total }}}{\tilde{y}_{\mathrm{ROR}}}$, respectively. The risk levels are assigned to three categories (low, medium, high). If $R_{\mathrm{EB}}<R_{\mathrm{APM}}$ (expected site-specific crash frequency lower than the normal number of crashes for a specific site type) there is no need for action (Level 0); in the other case the categorization is based on a threshold of the underlying distribution ( 0.9 quantile, cf. Fig. 4). The results of this procedure are illustrated in Fig. 5 for the Austrian motorway A2. The red segments satisfy the condition $R_{\mathrm{EB}} \geq R_{\mathrm{APM}}$ and $R_{\mathrm{EB}} \geq q_{0.9}=0.659$.

\subsection{Simulation of crash severity}

For the assessment of the injury severity, Finite Element Analysis (FEA) method was used. Five different objects (lightning pole, traffic sign with I beams, small and big traffic sign with tubular frame, tree) were identified as hazardous and simulated in LS Dyna.

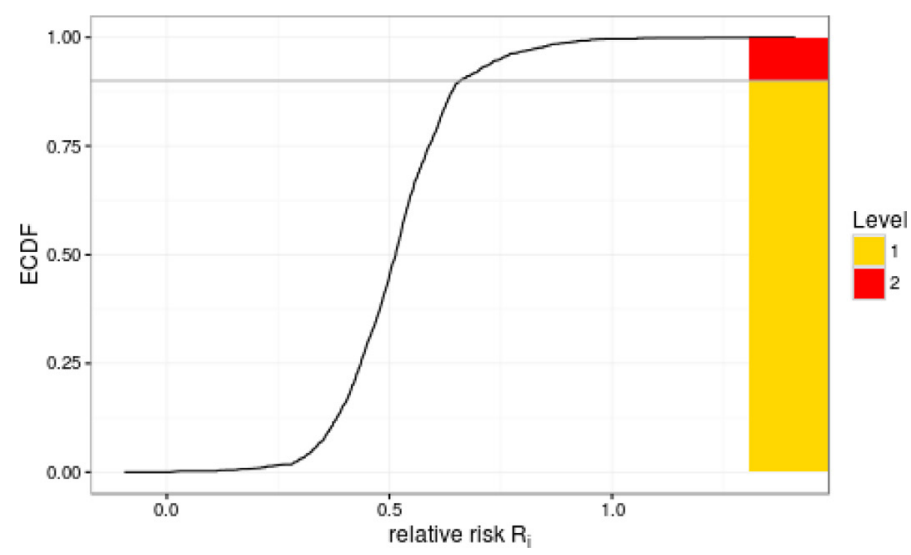

Figure 4: Empirical distribution of the relative risk for threshold-based risk categorization. 


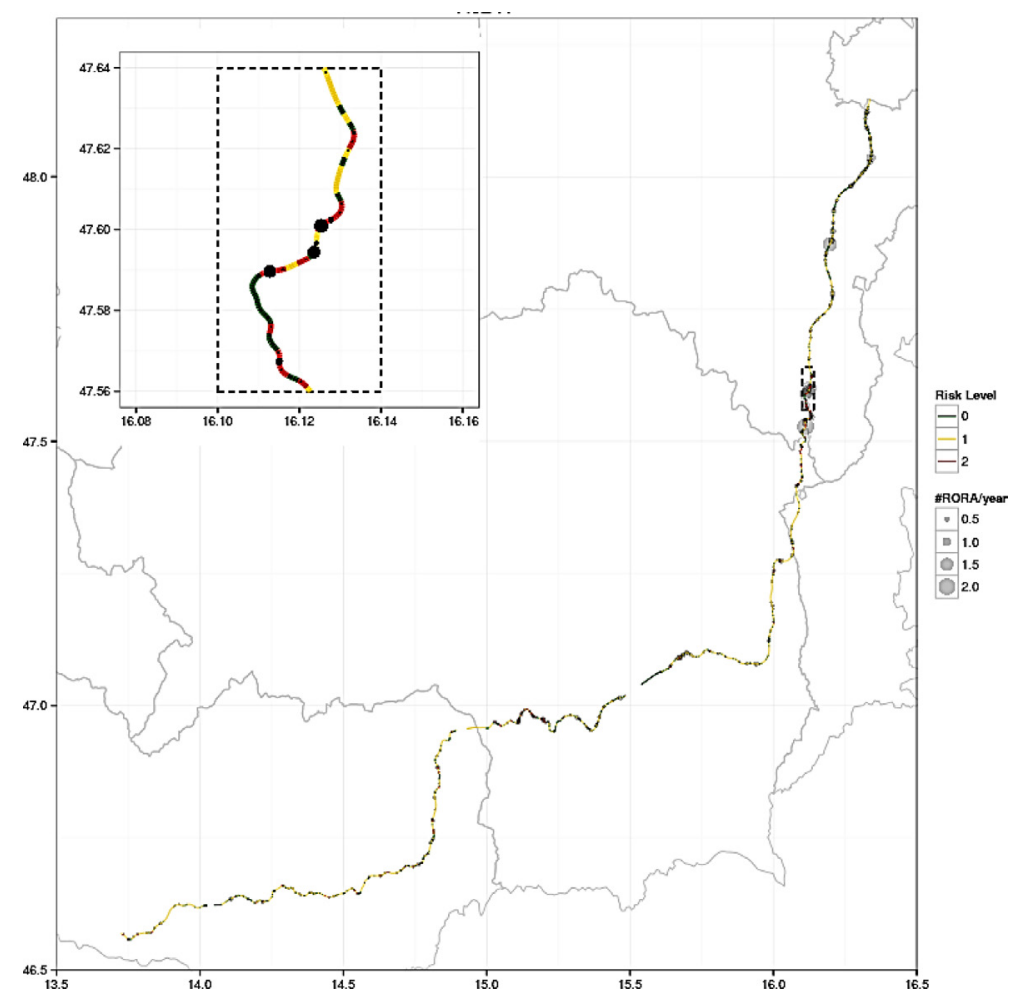

Figure 5: Classification of ROR risk on the A2 motorway (direction of travel: north, towards Vienna) and specifically for the Wechsel region.

It was decided to use a small vehicle for the impact simulation corresponding to requirements of EN 1,317 [9] and EN 12,767 [10] regulations. In Europe, these two standards regulate test procedures for the passive safety of roadside objects and for safety barriers. For the impact assessment, the Geo Metro vehicle model was used. This vehicle model is open access and provided by NCAC [11]. The total weight of the model is $926 \mathrm{~kg}$ and contains approximately 16,000 elements.

The stationary objects were frontal impacted with an impact angle of $20^{\circ}$. Impact speeds were $70 \mathrm{~km} / \mathrm{h}, 100 \mathrm{~km} / \mathrm{h}$ and $130 \mathrm{~km} / \mathrm{h}$, respectively. For the injury assessment, the Acceleration Severity Index (ASI) and Theoretical Head Impact Velocity (THIV) were calculated. The upper limit for ASI corresponded to the EN 1,317 impact severity level B which restricts an ASI below 1.4 and the THIV below $33 \mathrm{~km} / \mathrm{h}$ [12]. Furthermore, the energy absorption categories of the EN 12,767 were considered as additional decision criteria. The highest occupant safety level corresponded to an ASI below 1.0 and THIV below $33 \mathrm{~km} / \mathrm{h}$.

It was assumed that shielding roadside objects with an ASI value below 1.0 might not be necessary unless there are additional hazards present, e.g. fill slopes. Objects with an ASI between 1.0 and 1.4 should to be shielded if they are close to the road. Shielding objects with road side barriers when the ASI above 1.4 and THIV above $33 \mathrm{~km} / \mathrm{h}$ were considered mandatory. The simulation results are shown in Table 3 and 4. 
Table 3: ASI and THIV for different impact objects in frontal impacts.

\begin{tabular}{llcrcc}
\hline Object & Material & $\begin{array}{l}\text { Impact } \\
\text { angle }\left[{ }^{\circ}\right]\end{array}$ & $\begin{array}{l}\text { Impact speed } \\
{[\mathrm{km} / \mathrm{h}]}\end{array}$ & $\begin{array}{c}\text { ASI } \\
{[\mathrm{km} / \mathrm{h}]}\end{array}$ \\
\hline Lightning pole & aluminium & 0 & 100 & 3,6 & 54 \\
& & & 70 & 4,4 & - \\
Traffic sign with & steel & 20 & 70 & 0,35 & 8,5 \\
I-profile beams & & & 100 & 0,34 & 10,3 \\
& & & 130 & 0,30 & 4,8 \\
Small traffic sign with & \multirow{2}{*}{ steel } & 20 & 70 & 0,18 & 6,4 \\
tubular frame & & & 100 & 0,19 & 7,1 \\
& & & 130 & 0,24 & 7,4 \\
Big traffic sign with & steel & 20 & 70 & 0,79 & 30,4 \\
tubular frame & & & 100 & 0,65 & 21,4 \\
& & & 130 & 0,76 & 27,6 \\
\hline
\end{tabular}

Table 4: ASI and THIV for different tree diameters in frontal impacts.

\begin{tabular}{lcccccc}
\hline & $\begin{array}{c}\text { Tmpact speed } \\
{[\mathrm{km} / \mathrm{h}]}\end{array}$ & $\mathbf{5 0}$ & $\mathbf{1 0 0}$ & $\mathbf{1 5 0}$ & $\mathbf{2 5 0}$ & $\mathbf{3 5 0}$ \\
\cline { 3 - 7 } & 70 & 0,09 & 0,09 & 0,65 & 1,27 & 1,93 \\
\hline ASI & 100 & 0,07 & 0,09 & 0,42 & 0,88 & 1,62 \\
& $100^{1}$ & & & 0,74 & & \\
\multirow{4}{*}{ THIV } & 70 & 0,6 & 1,7 & 13,3 & 27,0 & 40,8 \\
& 100 & 0,5 & 2,0 & 18,2 & 17,4 & 29,4 \\
\hline
\end{tabular}

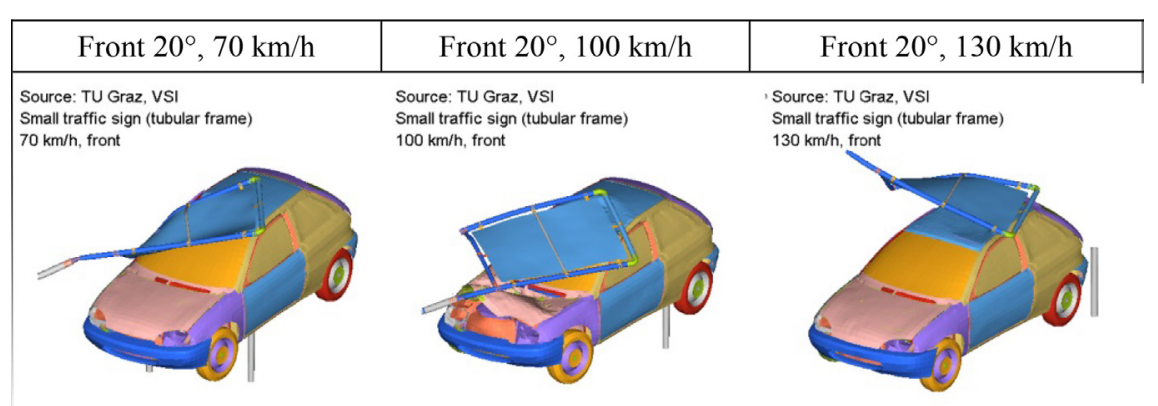

Figure 6: Simulation results of impact with the small traffic sign (tubular frame). 


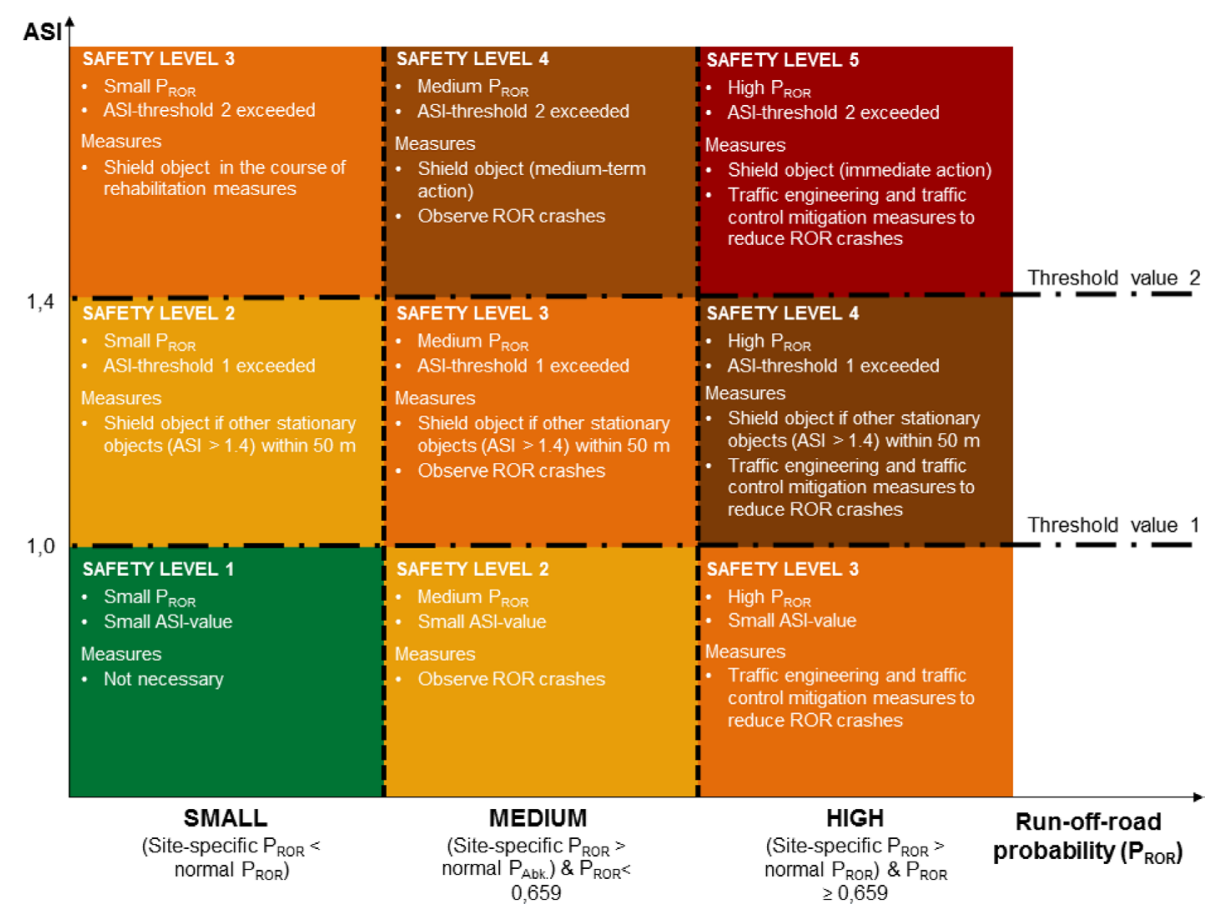

Figure 7: Risk matrix for ROR crashes on Austrian motorways.

According to Table 3, the structure of the lightning pole was too stiff, since the ASI and THIV values both exceeded the pre-defined limits. The simulation studies for the other objects showed that the ASI and THIV are well below 1.0. Hence, shielding these objects in case of a frontal impact would not be necessary. The damage to the car is shown in Fig. 6.

The FEA simulations with trees have shown a critical diameter starting from about $150 \mathrm{~mm}$. One important factor in the tree simulation is also the mesh size which indicates a higher ASI with a smaller mesh. This needs to be analysed in more detail including hard wood trees.

\section{RESULTS AND DISCUSSION}

The results of the APMs and the crash simulations were implemented in a risk matrix which gives the road operator a comprehensive tool to assess the ROR safety level of a stretch of road (see Fig. 7).

The abscissa of the matrix is divided into different ROR probability classes (small, medium, high) which is basically the output of the two developed APMs (see chapter 3.1). Furthermore, the ordinate was also split into several classes, clearly defined by ASI threshold values (threshold value $1=1.0$, threshold value $2=1.4$ ). The resulting $3 \times 3$ matrix offers varying courses of action due to ROR probabilities and crash severity levels.

The developed procedure offers the Austrian highway operator ASFINAG the opportunity to implement a risk-based decision support system on its network to reduce ROR crashes. In comparison to a traditional reactive approach, which relies on the analyses of available historical accident data to detect hazardous and accident prone situations, this 
approach is based on the principles of risk assessment (calculation of event probabilities and consequences). The results are highly objective and comparable over the whole road network.

\section{ACKNOWLEDGEMENT}

RISKANT is a research project funded within the 2011 Call "Transportation Infrastructure Research (VIF)" of the Austrian Research Promotion Agency (FFG) in conjunction with the Austrian highway operator ASFINAG and the Austrian railways (ÖBB).

\section{REFERENCES}

[1] Thomson, R., Fagerlind, H., Martinez, A.V., Amengual, A., Naing, C.L., Hill, J., Hoschopf, H., Dupre, G., Bisson, O., Kelkka, M., Van der Horst, R. \& Garcia, J.M., RISER - Roadside infrastructure for safer European roads, D06 European best practice for roadside design: guidelines for roadside infrastructure on new and existing roads, 2006.

[2] Statistics Austria: Annual analysis of road crashes on Austrian roads, 2007-2011, Vienna, 2011.

[3] Abdel-Aty, M., Lee, C., Park, J., Wang, J., Abuzwidah, M. \& Al-Arifi, S., Validation and application of highway safety manual (Part D) in Florida, department of transportation, Florida, 2014.

[4] FSV - Austrian Association for Research on Road - Rail - Transport (2006): RVS 13.01.15, Austrian road construction guidelines: quality assurance for structural maintenance - pavement management, assessment criteria for pavement condition measurements with the roadSTAR system, Vienna, 2006.

[5] Nelder, J.A. \& Wedderburn, R.W.M., Generalized linear models. Journal of the Royal Statistical Society, Series A, General, 135, pp. 370-384, 1972. http://dx.doi.org/10.2307/2344614

[6] Lord, D. \& Mannering, F., The statistical analysis of crash-frequency data: A review and assessment of methodological alternatives. Transportation Research Part A: Policy and Practice, 44(5), pp. 291-305, 2010.

http://dx.doi.org/10.1016/j.tra.2010.02.001

[7] Hauer, E., Harwood, D., Council, F. \& Griffith, M., Estimating safety by the empirical bayes method: a tutorial. Transportation Research Record, 1784(1), pp. 126-131, 2002. http://dx.doi.org/10.3141/1784-16

[8] Hauer, E., Observational Before-After Studies in Road Safety: Estimating the Effect of Highway and Traffic Engineering Measures on Road Safety, 1st edn., Pergamon: Oxford OX UK, Tarrytown NY USA, 1997.

[9] EN 1317-2: Road restraint systems - part 2: performance classes, impact test acceptance criteria and test methods for safety barriers including vehicle parapets, 15 July 2011.

[10] EN 12767: Passive safety of support structures for road equipment Requirements and test methods, 01 January 2008.

[11] National Crash Analysis Center (NCAC) Website: available at http://www.ncac.gwu. edu/vml/models.html (accessed 15 January 2016).

[12] EN 1317-2: Road restraint systems - part 2: performance classes, impact test acceptance criteria and test methods for safety barriers including vehicle parapets, 15 July 2011. 